RESEARCH ARTICLE

\title{
Impact of Moisture Stress and Bacillus altitudinis FD48 on Physiological Modulation and Seed Germination in Rice (Oryza sativa L.)
}

\author{
Shobana Narayanasamy and Sivakumar Uthandi \\ Department of Agricultural Microbiology, Tamil Nadu Agricultural University, Coimbatore-641 003
}

\begin{abstract}
The impact of moisture stress tolerant Bacillus altitudinis FD48 in promoting seed germination and physiological phenomenon under water deficit was evaluated. Rice seeds (Var C051) biotized with B.altitudinis FD48 enhanced the seed germination and seedling vigor index by $51.05 \%$ followed by Methylobacterium sp.,(37.3\%) moisture stress seedlings (-0.7 Mpa osmotic potential). Plant biomass, accumulation of proline and compatible sugars also increased in FD48 treated seeds under moisture stress. Further, the alpha amylase activity also accelerated with increase in moisture stress intensity. GCMS profiling of bacterial primed seed exudates revealed 35 diverse compounds belonging to the class viz., sugars, aminoacids, organic acids, flavones, prenol lipids and fatty acids. The $B$. altitudinis FD48 primed seeds alone released methoxy flavone which may act as a lure for recruiting beneficial rhizospheric bacteria. Hence, this study implies that seed priming with B.altitudinis FD48 is a promising approach for enhancing seed germination and seedling establishment in rice for drought prone areas and subsequent recruitment of beneficial bacteria that promotes plant growth and fitness.
\end{abstract}

Received : $22^{\text {nd }}$ January, 2020

Revised : $07^{\text {th }}$ February, 2020

Accepted : $25^{\text {th }}$ February, 2020

Keywords: Moisture stress, Bacillus, seed germination, seed exudates.

\section{INTRODUCTION}

Rice (Oryza Sativa L.) is an important cereal crop, serves as a staple food for more than half billion people across the globe contributing $20 \%$ $80 \%$ of daily calorie requirement. Rice crop is delicate to moisture stress that critically impairs the production of 23 billion hectares of rainfed rice in Asia (Kumar et al., 2015). Unprecedented drought and erratic distribution of rainfall due to climate change are the major bottlenecks in rainfed regions, mainly for aerobic rice cultivation. Among the plant growth and developmental stages of rice plant, seed germination is a critical phase of plant development that plays a pivotal role in seedling establishment. Due to low water availability, the growth phenomenon was affected (Bewley, 1997). Multiple endogenous elements regulate the seed germination, including plant hormones, hydrolytic enzymes and environmental factors viz., temperature, water availability, nutrients and light (Weitbrecht et al., 2011; Cho et al., 2012). The enzyme amylase hydrolyzes endosperm starch into sugars that provide energy for both shoot and root growth (Nauriere et al. 1992). However, the activity of amylase is affected by osmotic stress resulting in impaired carbohydrate metabolism (Kaur et al.
2000; Zeid \& Shedeed 2006). This sheds light on the ability of seeds to combat water deficit conditions. Hence, the successful establishment of crops in drought-prone regions highly depends on the inherent potential of the seed viz., the speed and germination consistency (Arjenaki et al. 2011). Germinating seed and its surrounding soil represent an excellent niche for microbial colonization known as the spermosphere. Similar to the rhizospheric region, the spermosphere is formed by the carbon compounds deposited into the soil when the seed initiates the germination process. Such seed exudations influence the microbial activity around the seeds and many of which exert positive impacts on plant growth and fitness. However, the microbial diversity in the spermosphere and their role in plant-microbial interactions remain unexplored (Nelson, 2004).

Plant growth-promoting bacteria (PGPB) has been well established to improve the plant growth and productivity of crop plants under moisture stress (Grover et al., 2014; Punitha et al., 2019). IAA production, enzyme activity and phosphate solubilization are the most common plant growthpromoting mechanisms associated with PGPB to enhance plant growth and productivity (Datta et al., 2011). IAA extrapolates root architectural traits 
such as root length, surface area and root hair intensity, thereby enhances rice seed germination and seedling establishment (Ng et al., 2012). Moreover, phosphorus is an essential macronutrient for rice growth and development. Under moisture stress or in dry soil, P solubilization solely depends on the phosphate solubilizing bacteria through the production of organic acids and phosphatase enzyme (Gyaneshwar et al., 2002). Plant growthpromoting bacterial genera including Bacillus ( $\mathrm{Ng}$ et al., 2012), Enterobacter (Gupta et al., 1998) and Corynebacterium have been reported to improve the plant growth and fitness under drought. Seed priming with $B$. amyloliquefaciens improved the shoot and root length in Arabidopsis under drought and salinity stress (Preeti et al., 2002; Ryu et al., 2004). Therefore, we hypothesize that inoculation of osmotic stress-tolerant PGPB with the potential to solubilize phosphate and IAA production during moisture stress ensures the establishment of rice seedlings.

Our previous studies suggest that Bacillus altitudinis FD48 possess plant growth-promoting attributes such as IAA production, $\mathrm{P}$ and $\mathrm{Zn}$ solubilization, siderophore and ACC deaminase production (Kumar et al., 2017). Besides, it can also able to tolerate the high osmotic potential of -1 Mpa (30\% PEG 6000). With this background, the present study aims to demonstrate the efficacy of $B$. altitudinis FD48 on seed germination under induced moisture stress.

\section{MATERIAL AND METHODS}

\section{Bacterial strain and culture conditions}

Bacterial strain, Bacillus altitudinis FD48 used in this study (previously isolated from the phyllosphere of rice cultivar ADT43), was obtained from the Department of Agricultural Microbiology, Tamil Nadu Agricultural University, Coimbatore. The FD48 strain grown in LB broth, incubated at $28^{\circ} \mathrm{C}$ at $120 \mathrm{rpm}$ was used for subsequent studies.

\section{Seed biotization}

Rice (Oryza sativa L.) cultivar C051 seeds obtained from Paddy Breeding Station, Tamil Nadu Agricultural University, Coimbatore, India, was used in this study. De-husked healthy seeds were surface sterilized in $0.1 \% \mathrm{HgCl}_{2}$ for 3 mins and subsequently in $70 \%$ ethanol for $1 \mathrm{~min}$ followed by five washes with sterile distilled water. Then the surface-sterilized seeds were primed with bacterial suspensions $\left(10^{9}\right.$ cfu $\mathrm{ml}^{-1}$ ) of $B$. altitudinis FD48 and Methylobacterium sp. TNAU1 (PPFM) (as a positive check) for $1 \mathrm{~h}$ at $28 \pm 2{ }^{\circ} \mathrm{C}$. The treated seeds were placed on sterile filter paper in Petri dishes $(9 \mathrm{~cm})$ moistened with sterile distilled water or $5,10,15,20$, and $25 \%$ of polyethylene glycol (PEG 6000) concentration equivalent to osmotic potentials of $(-0.30,-0.51$,
-0.58 and -0.80 MPa respectively) were incubated for five days in plant growth chamber with a relative humidity of $60 \%$ and $12 \mathrm{~h}$ light $\left(200\right.$ moles $\mathrm{m}^{-2} \mathrm{~s}$ $\left.{ }^{1}\right)$ at $28{ }^{\circ} \mathrm{C}$. Five replicates with 50 seeds were maintained for each treatment. Seeds immersed in sterile distilled water served as control. Petri dishes were sealed in order to prevent evaporation and seeds were considered to be germinated when the radical length attains for at least $2 \mathrm{~mm}$.

\section{Seed germination analysis}

Seed germination percentage is the average number of seeds germinated over the period. In this study, germination percentage was calculated on fifth day using the standard formulae:

\section{Seed Vigour index}

Seed vigor index was examined after five days of incubation according to the formula based on the product of germination (\%) and seedling length (cm).

\section{Quantitative analysis of enzyme activity during germination}

The $\alpha$-amylase activity in the crude extract of germinated seeds was determined, according to Muscolo et al. (2014). Approximately 10 germinated seeds from each treatment with different stress levels with PEG $6000(0,5,10,15,20,25)$ were homogenized in 1:4 w/v distilled water using chilled pestle and mortar. The extract was centrifuged at $14,000 \mathrm{rpm}$ for $30 \mathrm{~min}$. Collected supernatant filtered through muslin cloth was used for the quantitative assay of $\alpha$-amylase (EC 3.2.1.1).

\section{Osmolytes content}

Free proline content in the sample was detected based on the method described by Bates et al. (1973). Approximately 300mg of plant sample homogenized in $5 \mathrm{ml}$ of $3 \%$ sulfosalicylic acid was centrifuged at $3000 \mathrm{~g}$ for 20 mins. The collected supernatant was mixed with $2 \mathrm{ml}$ of glacial acetic acid and $2 \mathrm{ml}$ of ninhydrin. The mixture was boiled at $100{ }^{\circ} \mathrm{C}$ for 25 mins and mixed with $4 \mathrm{ml}$ of toluene. Then the absorbance of the extract was measured in Spectrophotometer (Spectramax I3x) at $535 \mathrm{~nm}$. Anthrone method was followed to determine the total soluble sugar content in the plant sample (Yemn \& Willis 1954).

\section{Collection of Seed exudates and GC-MS analysis}

To assess the effect of bacterization on seed metabolite pattern, the seed exudates were collected and profiled using GC-MS (Shu et al., 2008). Bacterial primed and control seeds (50 seeds) were placed in $50 \mathrm{ml}$ of sterile MilliQ water and incubated for $12 \mathrm{hrs}$ at $28^{\circ} \mathrm{C}$ on a rotary shaker at $120 \mathrm{rpm}$. The samples were concentrated and passed through a $0.2 \mu \mathrm{m}$ membrane. Consequently, the solution was mixed with an equal quantity of ethyl acetate 
followed by overnight. The separated solvent phase was concentrated in a flash evaporator and the crude metabolites extracted in $1 \mathrm{ml}$ methanol was subjected to GC-MS analysis (Perkin Elmer GC-MS Clarus ${ }^{\circledR}$ SQ 8) equipped with DB-5MS (Agilent, USA) capillary standard non-polar column $(0.25 \mathrm{~mm}$ OD $x$ $0.25 \mu \mathrm{m}$ ID x $30 \mathrm{~m}$ length). The instrument was set to an initial temperature of $40{ }^{\circ} \mathrm{C}$ and the injection port temperature was ensured at $220{ }^{\circ} \mathrm{C}$, interface temperature set $250{ }^{\circ} \mathrm{C}$, source kept at $220{ }^{\circ} \mathrm{C}$, oven temperature-programmed as $75^{\circ} \mathrm{C}$ for $2 \mathrm{~min}$, $150{ }^{\circ} \mathrm{C} @ 10^{\circ} \mathrm{C} / \mathrm{min}$, up to $250^{\circ} \mathrm{C}$ at $10^{\circ} \mathrm{C}$ permin. The GC conditions were: $1: 12$ split, helium carrier at 20 psi. The MS conditions were: positive ion mode, electron impact spectra at $70 \mathrm{eV}$. The mass spectral scan range was set at 50 to $600 \mathrm{Da}$.

\section{Statistical analysis}

All data were statistically analyzed in Microsoft Excel and add-in with XLSTAT Version 2016.04.325250 (XLSTAT, 2016). Significant differences among the treatments were statistically analyzed using analysis of variance (ANOVA) and Duncan's Multiple Range Test (DMRT) at $p<0.05$ significance level.

\section{RESULTS AND DISCUSSION}

\section{Germination percentage and vigor index under moisture stress}

In the present investigation, biotization of rice seed with B.altitudinis FD48 enhanced the germination and seedling growth under induced

Table 1. Effect of biotization on seed germination, vigor index and total biomass

\begin{tabular}{|c|c|c|c|c|c|c|c|c|c|}
\hline \multirow{2}{*}{$\begin{array}{r}\text { PEG } \\
\text { (\%) }\end{array}$} & \multicolumn{3}{|c|}{ Germination Percentage } & \multicolumn{4}{|c|}{ Vigor Index (\%) } & \multicolumn{2}{|c|}{ Fresh weight (mg) } \\
\hline & Control & FD48 & PPFM & Control & FD48 & PPFM & Control & FD48 & PPFM \\
\hline $0 \%$ & 100 & 100 & 100 & 199.66 & 243.22 & 239.66 & 343.335 .70 & 3702.73 & 3508.84 \\
\hline $5 \%$ & 94 & 97 & 96 & 185.32 & 199.16 & 199.76 & 3296.11 & 362.134 .36 & 35211.84 \\
\hline $10 \%$ & 71 & 87 & 88 & 162.32 & 191.31 & 192.14 & 2132.73 & 292.94 .10 & 280.7710 .17 \\
\hline $15 \%$ & 64 & 71 & 69 & 144.89 & 158.98 & 155.43 & 163.822 .60 & 208.2613 .72 & 195.53 .46 \\
\hline $20 \%$ & 51 & 60 & 58 & 40.32 & 51.34 & 48.65 & 46.584 .62 & 79.274 .06 & 74.271 .20 \\
\hline $25 \%$ & 22 & 32 & 30 & 35.55 & 44.32 & 42.22 & 6.173 .18 & 19.181 .20 & 16.20 .88 \\
\hline
\end{tabular}

Control - Absolute control without any treatments, FD48- B.altitudinis FD48 and PPFM- Methylobacterium sp. TNAU1. Values are mean ( \pm standard error) $(n=5)$.

moisture stress. Seed priming with PGPBs significantly promoted the seed germination and seedling establishment under moisture stress (Kalita et al., 2015). Germination started irrespective of all treatments (Table 1 and Fig.1).
However, an increase in PEG concentration $(-0.045,-0.14,-0.277,-0.46,-0.7 \mathrm{MPa}$ of osmotic potential) considerably reduced the germination percentage compared to their respective controls. On exposure to sudden moisture stress of $-0.27 \mathrm{MPa}$,

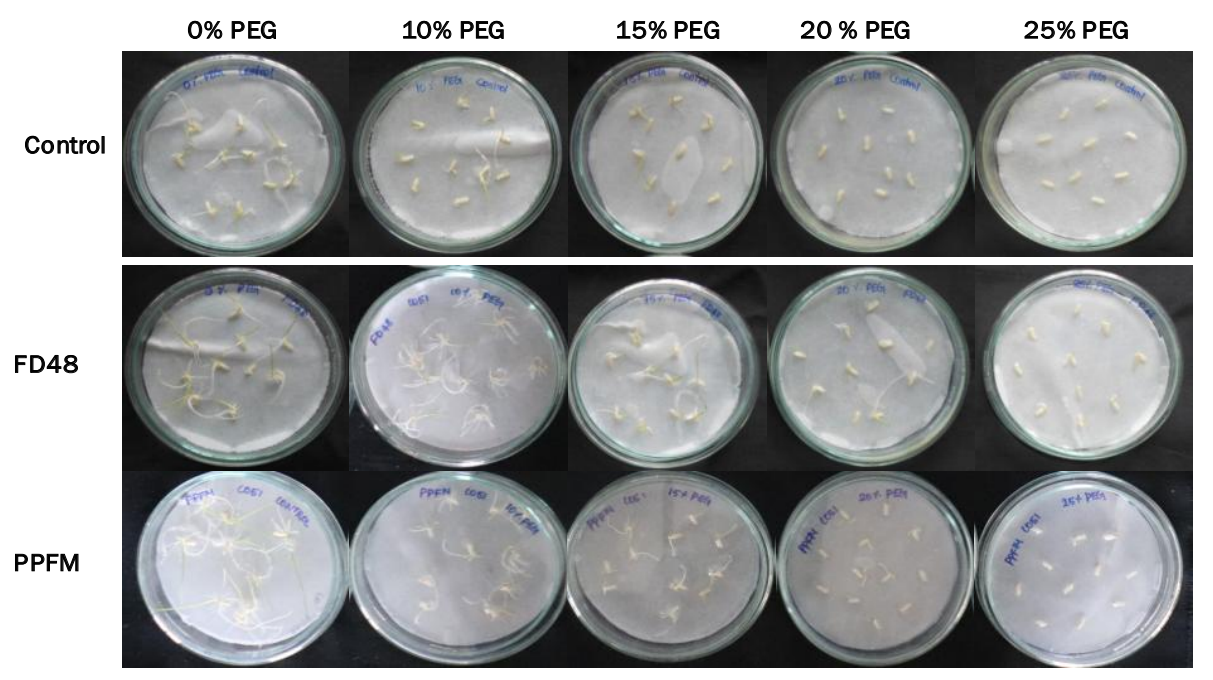

Figure 1. The effect seed biotization on germination of C051 seeds at different PEG 6000 concentration under in vitro plate assay.

Control - Absolute control without any treatments, FD48- B. altitudinis FD48 and PPFM- Methylobacterium sp. TNAU1 (PPFM)

reduction in seed germination was recorded, whereas control seeds registered $100 \%$ seed germination after 3 DAS. A drastic reduction was observed in germination percentage on exposure to osmotic potential of - 0.7 MPa (25\% PEG 6000). In general, the seeds primed with strains of $B$. altitudinis FD48 and Methylobacterium sp., significantly improved the seed germination over control under induced moisture stress. Among the treatments, osmotic stress imposed seeds treated 
with FD48 and Methylobacterium sp at $-0.7 \mathrm{MPa}$ accounted for $44 \%$ and $32 \%$ increase in germination percent respectively over uninoculated control. Furthermore, bacterization also increased the seed vigor index over control under moisture stress. The results suggest that priming seeds with moisture stress tolerant PGP bacterial inoculants accelerated the glucose metabolism of seeds imposed with moisture stress, as explained by Sun et al. (2010).

Table 2. Root length (cm) and $\alpha$-amylase activity ( $\mu$ moles of reducing sugars formed $\mathrm{min}^{-1} \mathrm{~g}^{-1} \mathrm{FW}$ ) of rice seeds under different concentrations of PEG 6000 on 3days of germination

\begin{tabular}{ccccccc}
\hline \multirow{2}{*}{ PEG (\%) } & \multicolumn{3}{c}{ Root length $(\mathbf{c m})$} & \multicolumn{2}{c}{$\begin{array}{c}\alpha \text {-Amylase content } \\
\left(\mu \text { moles of reducing sugars formed } \mathbf{~ m i n}^{-1} \mathbf{g}^{-1} \mathrm{FW}\right)\end{array}$} \\
\cline { 2 - 7 } & Control & FD48 & PPFM & Control & FD48 & PPFM \\
\hline $\mathbf{0 \%}$ & $0.95 \pm 0.01^{\mathrm{c}}$ & $1.66 \pm 0.03^{\mathrm{a}}$ & $1.53 \pm 0.05^{\mathrm{b}}$ & $16.44 \pm 0.51^{\mathrm{b}}$ & $18.55 \pm 0.33^{\mathrm{a}}$ & $18.33 \pm 0.25^{\mathrm{a}}$ \\
$\mathbf{5 \%}$ & $0.93 \pm 0.01^{\mathrm{b}}$ & $1.38 \pm 0.02^{\mathrm{a}}$ & $1.33 \pm 0.05^{\mathrm{a}}$ & $14.33 \pm 1.15^{\mathrm{b}}$ & $18.62 \pm 0.41^{\mathrm{a}}$ & $17.69 \pm 0.36^{\mathrm{a}}$ \\
$\mathbf{1 0 \%}$ & $0.73 \pm 0.01^{\mathrm{b}}$ & $1.19 \pm 0.02^{\mathrm{a}}$ & $1.17 \pm 0.01^{\mathrm{a}}$ & $15.16 \pm 0.20^{\mathrm{a}}$ & $16.22 \pm 0.61^{\mathrm{a}}$ & $16.15 \pm 0.54^{\mathrm{a}}$ \\
$\mathbf{1 5 \%}$ & $0.62 \pm 0.01^{\mathrm{b}}$ & $0.94 \pm 0.08^{\mathrm{a}}$ & $0.87 \pm 0.04^{\mathrm{a}}$ & $13.75 \pm 0.56^{\mathrm{b}}$ & $15.35 \pm 0.22^{\mathrm{a}}$ & $15.12 \pm 0.10^{\mathrm{a}}$ \\
$\mathbf{2 0 \%}$ & $0.25 \pm 0.01^{\mathrm{b}}$ & $0.61 \pm 0.01^{\mathrm{a}}$ & $0.56 \pm 0.03^{\mathrm{a}}$ & $11.08 \pm 0.22^{\mathrm{b}}$ & $13.18 \pm 0.20^{\mathrm{a}}$ & $13.13 \pm 0.16^{\mathrm{a}}$ \\
$\mathbf{2 5 \%}$ & $0.17 \pm 0.02^{\mathrm{b}}$ & $0.25 \pm 0.01^{\mathrm{a}}$ & $0.21 \pm 0.00^{\mathrm{a}}$ & $8.70 \pm 0.31^{\mathrm{b}}$ & $9.4 \pm 0.15^{\mathrm{a}}$ & $8.94 \pm 0.20^{\mathrm{ab}}$ \\
\hline
\end{tabular}

Control - Absolute control without any treatments, FD48- B.altitudinis FD48 and PPFM- Methylobacterium sp. TNAU1. Values are mean ( \pm standard error) ( $\mathrm{n}=5$ ) and values followed by the same letter in each column are not significantly different from each other on the observation day as determined by DMRT ( $p \leq 0.05$ ).

Moreover, the enzymes involved in the seed germination process shorten the lag and metabolic phase in the presence of growth-promoting phyllosphere bacterium B. altitudinis FD48
(Delshadi, 2015). Bandeepa et al. (2018) that osmotolerant rhizobacterial strains enhanced the seed germination and vigor index under induced moisture stress disclose similar results.

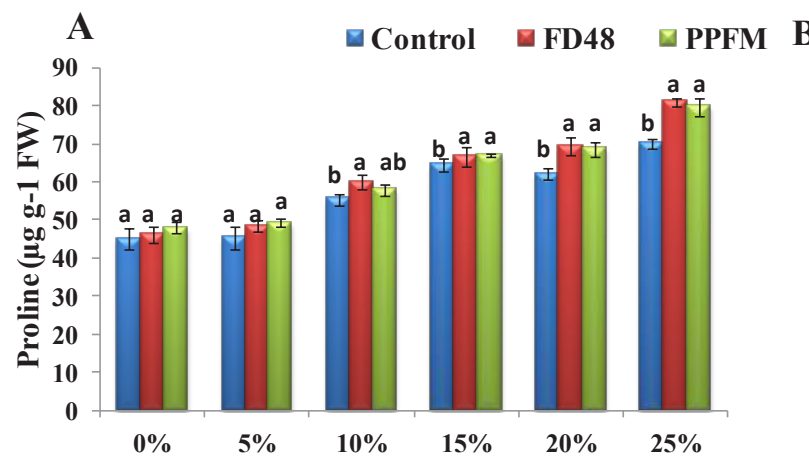

PEG 6000 concentration

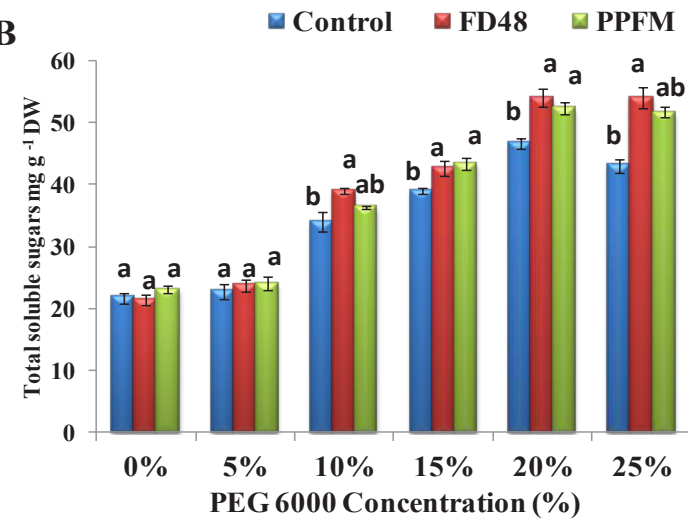

Figure 2. Total proline content (A) and soluble sugars (B) in rice seeds biotized with PGPB at different concentrations of PEG 6000

Control - Absolute control without any treatments, FD48- B.altitudinis FD48 and PPFM- Methylobacterium sp. TNAU1. Values are mean \pm standard error) $(n=5)$ and values followed by the same letter in each column are not significantly different from each other on the observation day as determined by DMRT $(p \leq 0.05)$

\section{Plant biomass}

IAA is an essential phytohormone that regulates root architecture and sustains the root shoot growth (Kaufman et al., 1995). The results of data were on variance analysis (Table. 2) showed that seed biotization and different levels of drought stress has a significant effect on the root length ( $p<0.05)$. Mean comparison values showed that treatments with FD48 and Methylobacterium sp significantly influenced the root length $(53 \%$ and $48 \%$ respectively) over control on 5DAS at the level of -0.7 MPa. A significant increase in root length might be due to endogenous IAA produced by the PGPB strains that enhanced the root growth under osmotic stress (Khalid et al., 2004).
Likewise, the mean values of total biomass showed a steady decline with an increase in the intensity of stress level (Table.1.). At the maximum level of stress (-0.7 MPa), FD48 and Methylobacterium sp treated seeds registered $34 \%$ and $31 \%$ increase of total biomass over control. Also, under non-stressed conditions, FD48 significantly influenced the total biomass followed by Methylobacterium sp, when compared to uninoculated control. The present investigation showed that water deficit stress in uninoculated control plants reduced the shoot length. In general, drought stress increases the ethylene concentration of the plant. The crucial factor that prevents auxin transfer and arrests plant height is ethylene acetic

$107|1-3| 56$ 
acid (Vacheron et al., 2013). The reduced biomass, because of moisture stress could be attributed to impaired photosynthesis rate due to the dehydration and reduced source-sink relationship (Jamshidi et al., 2012). Hence it can be concluded that priming seeds with PGPB, FD48 and Methylobacterium $\mathrm{sp}$ in this case triggered auxin production and diminished the ethylene level under moisture stress. Similar results have also been reported by Sarcheshmehpour et al. (2013) and Rana et al. (2015) on the positive impact of plant-growth- promoting rhizobacteria on the growth of pistachio, rice and wheat under drought stress respectively.

\section{Osmolytes on seedling establishment}

Accumulation of osmolytes and compatible solutes has been reported to increase under water deficit conditions. Osmolytes help the plants to cope with moisture stress by maintaining the osmotic turgor in cells (Grover et al., 2014; Lata et al., 2015). Accordingly, the present study also reported a gradual increase in proline and total soluble sugars

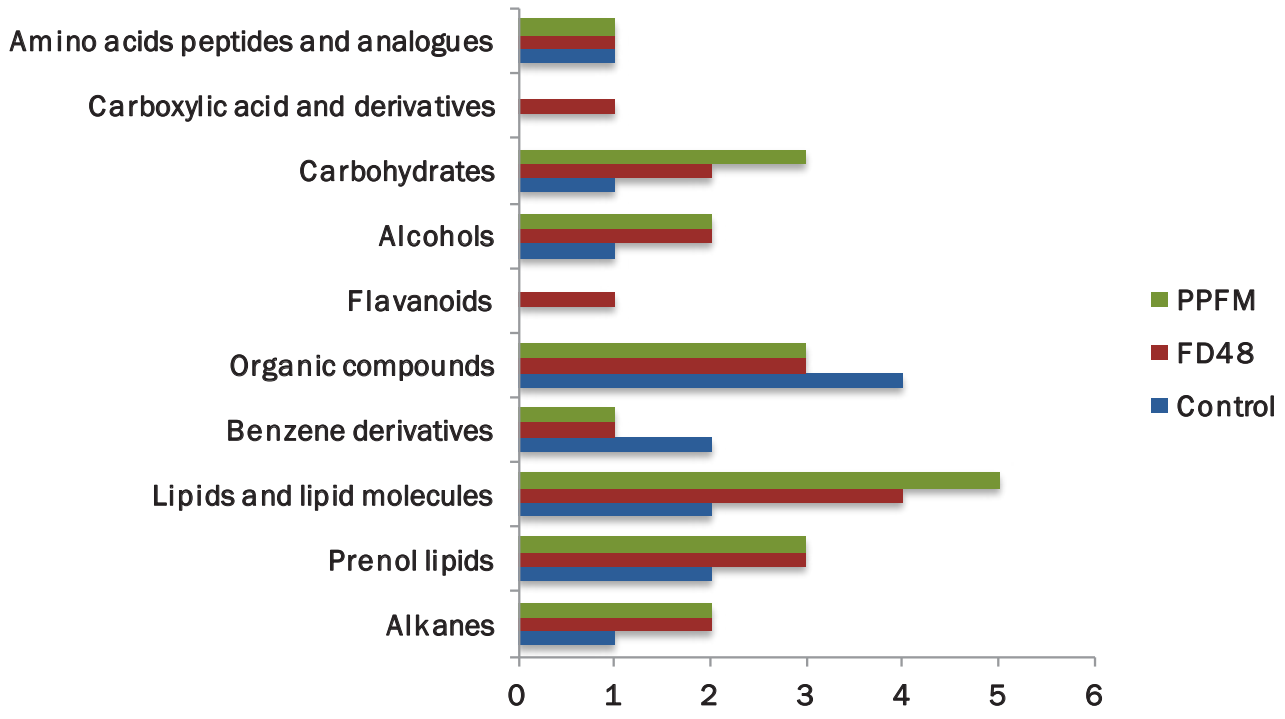

Figure 3. Metabolites detected in seed exudates of biotized rice seeds (cultivar C051) based on their differences in relative abundance.

Control - Absolute control without any treatments, FD48- B.altitudinis FD48 and PPFM- Methylobacterium sp. TNAU1.

in rice seedlings under different levels of moisture stress. However, the proline and soluble sugar content of PGP bacterial primed seedlings showed a significant increase over uninoculated control (Fig. $2 a$ and $2 b$ ). The data on variance analysis showed that there is no significant difference among the PGPB strains on total soluble sugar content in nonstress (NS) treatments.

Interestingly, at high-stress intensity (-0.7 MPa), the maximum soluble sugar content of $54 \mathrm{mg} \mathrm{g}^{-1}$ DW and $51 \mathrm{mg} \mathrm{g}^{-1} \mathrm{DW}$ was related to the treatments with FD48 and Methylobacterium sp respectively. Meanwhile, FD48 and Methylobacterium sp treated seeds accumulated maximum proline content under moisture stress conditions $(-0.7 \mathrm{MPa})$ when compared to control on 5 DAS. The results of the study suggested that the accumulation of proline and compatible solutes under moisture stress guard the plants against osmotic stress, by maintaining the redox homeostasis through stabilizing membrane proteins, and ROS scavenging (Tiwari et al., 2016). Hence, increased seed viability, GP and total biomass in bacterized stressed plants might be due to osmotic adjustment as a result of increased osmolyte synthesis. Similar observations have been reported in rice seedlings attenuated with Bacillus pumilis, subjected to salt stress (Khan et al., 2016) and in maize seedlings under drought stress (Garcia et al., 2017).

\section{Alpha-amylase activity}

Alpha-amylase is an essential enzyme involved in the hydrolytic breakdown of starch into simple sugars in order to provide energy for the shoot and root development. Water deficit stress affects $\alpha$-amylase activity and drastically reduces seed germination. The mean values of $\alpha$-amylase activity on 3DAS exhibited a gradual decrease with an increase in PEG concentration. However, the data variance analysis suggested no significant difference among the treatments related to NS (Table.2). In comparison to uninoculated moisture stressed seeds, the inoculated seeds enhanced the amylase activity by $8 \%$ and 3\% (FD48 and Methylobacterium $\mathrm{sp})$ respectively. During seed germination, starch hydrolysis is mediated by the enzyme $\alpha$-amylase, which produces soluble oligosaccharides essential 
for other metabolic functions (Kaur et al., 2005). Accordingly, the enhanced $\alpha$-amylase activity due to bacterial priming suggests better bioconversion of starch into other oligosugars.

\section{Seed exudates profile}

Seed exudates are a key to prompt the rhizobacterial colonization, which can impact on the plant growth and health (Nelson, 2004). During germination, seeds exude contain metabolites that influence their immediate biotic and abiotic environments. The current investigation revealed 35 metabolites belonging to the class viz., (Fig.3) sugars (glycerol, glycine), aliphatic organic acids (fumaric acid), fatty acids (myristic caid, palmitic acid hexadecanoic acid, octadecanoic acid, tridecanoic acid), prenol lipids (squalene) and alcohols (ethanol, propinaldehyde, 1-hexadecanol). The Heat map analysis showed the distribution of seed exuded metabolites among the treatments (Fig.4). Row Z-score $(>1)$ showed an increase in the relative abundance of the metabolites.

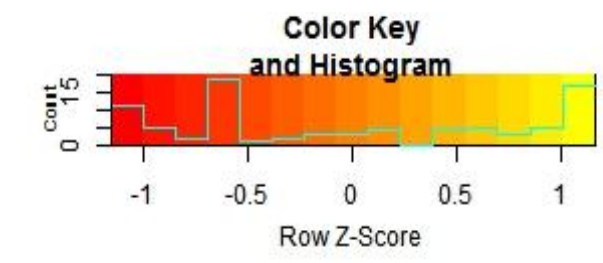

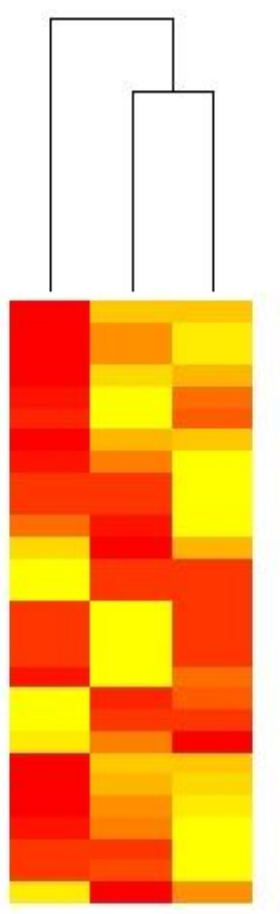

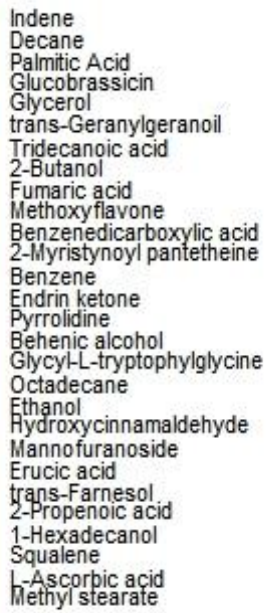

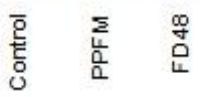

Figure 4. Distribution pattern of metabolites in seed exudates of rice seeds (C051) due to seed priming with B. altitudinis FD48 and Methylobacterium sp. TNAU1 (PPFM)

Control - Absolute control without any treatments, FD48- B. altitudinis FD48 and PPFM- Methylobacterium sp. TNAU1.

More diverse compounds were found in treatments of FD48 primed stressed seeds when compared to Methylobacterium sp and uninoculated control. The key metabolites with relevance to moisture stress tolerance are glycine, fumaric acid, fatty acids, flavones, squalene and ethanol. More precisely, the enhanced tolerance of bacteria primed moisture stressed seeds might be due to the maintenance of cell turgidity by these osmoregulants mediated by FD48 and Methylobacterium sp. Fumaric acid solubilizes phosphorus and makes it more available to the pre-germinating root primordia (Ng et al., 2012). Seed exudates can also be involved as the lure of rhizosphere micro-organisms and can modulate significant bacterial properties that impart the ability to adhere and grow competitively in the vicinity of seeds (Schiltz et al., 2015). Accordingly, methyl flavones were pinned in the seeds primed with FD48 when compared to Methylobacterium $\mathrm{sp}$. These flavone derivatives would help in seedling establishment and recruits beneficial microbial interactions that facilitate plant health and fitness. In addition, Martins et al., (2018) showed that seed exudates of bean seed promoted the growth of $B$. amyloliquefaciens ALB629 and biofilm formation. Herein the present investigation also envisages better colonization of the bioinoculants $(B$. altitudinis FD48 and Methylobacterium sp (PPFM)) over the surface of moisture stressed seeds.

\section{CONCLUSION}

The present study revealed that rice seed bacterized with moisture stress-resilient phyllosphere bacterium, Bacillus altitudinis FD48 promoted seed 
germination and vigor index under induced moisture stress. The mechanistic insights further showed the accumulation of osmolytes, compatible sugars and enhanced amylase activity, ensuring root and shoot growth. Further, seed exudates unraveled vital metabolites such as glycine, fumaric acid, squalene, methoxy flavone and other fatty acids that would help in seedling establishment and recruiting other beneficial microbial interactions. Therefore, our finding fosters a bio-inoculant for seed priming that could be adopted in drought-prone regions to increase the seed establishment and plant fitness.

\section{ACKNOWLEDGEMENT}

This study was supported by the Ministry of Human Resource Development, Government of India through MHRD-FAST-CoE (F.No.5-6/2013-TSVII) sanctioned to SU.

\section{REFERENCES}

Arjenaki, F.G., Dehaghi, M.A. and R. Jabbari. 2011. Effects of priming on seed germination of Marigold (Calendula officinalis). Adv. Environ. Biol., 5:276280.

Bandepppa, Paul., Sangeeta, A., Manjunatha, C., Rathi, C.S. and M. Singh. 2018. Characterization of osmotolerant rhizobacteria for plant growth promoting activities in vitro and during plantmicrobe association under osmotic stress. Ind. J. Exp. Biol. 56: 582-589.

Bates, L.S., Waldren, R.P. and I.D. Teare. 1973. Rapid determination of free proline for water stress studies. Plant Soil. 39:205-207.

Bewley, J.D.and M. Black.1994. Seeds: physiology of development and germination. New York: Plenum Press.

Cho, J. N., Ryu, J. Y., Jeong, Y.M., Park, J., Song, J. J. and R.M Amasino. 2012. Control of seed germination by light-induced histone arginine demethylation activity. Dev. Cell. 22:736-748.

Datta, M., Palit, R., Sengupta, C., Pandit, M.K. and S. Banerjee. 2011. Plant growth promoting rhizobacteria enhance growth and yield of chilli (Capsicum annuum L.) under field conditions. Aust J. Crop Sci. 5 (5): 531-536.

Delshadi, S., Ebrahimi, M. and E. Shirmohammadi. 2017. Influence of plant-growth-promoting bacteria on germination, growth and nutrients' uptake of Onobrychis sativa L. under drought stress. J. Plant Interact. 12(1): 200-208.

García, J.E., Maroniche, G., Creus, C., Suárez-Rodríguez, R., Ramirez-Trujillo, J.A. and M.D. Groppa. 2017. In vitro PGPR properties and osmotic tolerance of different Azospirillum native strains and their effects on growth of maize under drought stress. Microbiol. Res. 202:21-29.

Grover, M., Madhubala, R., Ali, S.Z., Yadav, S.K. and B. Venkatsewarlu. 2014. Influence of Bacillus spp. strains on seedling growth and physiological parameters of sorghum under moisture stress conditions. J. Basic. Microbiol. 54: 951-96.
Gupta, A., Saxena, A.K., Gopal, M. and K.V.B.R Tilak. 1998. Effect of plant growth promoting rhizobacteria on competitive ability of introduced Bradyrhizobium sp. (Vigna) for nodulation. Microbiol Res. 153:113-117.

Gyaneshwar, P., Kumar, G.H., Parekh, L.J. and P.S. Poole. 2002. Role of soil microorganisms in improving $P$ nutrition of plants. Plant Soil. 245:83-93.

Jamshidi N, Shirani Rad AH, TakhtChin F, Nazeri P, Ghafari M. 2012. Evaluation of rapeseed genotypes under drought stress condition. Crop Eco-Physiol. 3:323-338.

Kalita, M., Bharadwaz, M., Dey, T., Gogoi, K., Dowarah, P., Unni, B.G., Ozah, D. and I. Saikia. 2015. Developing novel bacterial based bioformulation having PGPR properties for enhanced production of agricultural crops. Ind. J. Exp. Biol. 53(1): 56-60.

Kaufman, P.B., Wu , L.L., Brock, T.G. and K. Kim. 1995. Hormones and the orientation of growth. In: Davies P.J. (ed) Plant hormones: Physiology, bio-chemistry and molecular biology. Netherlands, Kluwer Academic, pp 547-570

Kaur, R., Liu, X., Goerup, O., Zhang, A., Yuan, X., Balk, S.P., Schneider, M.C. M.L. Lu. 2005. Activation of $p$ 21- activated kinase 6 by MAP kinase 6 and p 38 MAP kinase. J. Bio. Chem. 280:3323-3330.

Kaur, S.,Gupta, A.K. and N. Kaur. 2000. Effect of GA3, kinetin and indole acetic acid on carbohydrate metabolism in chickpea seedlings germinating under water stress. Plant Growth Regul. 30:61-70.

Khalid A., Arshad, M. and Z.A. Zahir. 2004. Screening plant growth promoting rhizobacteria for improving growth and yield of wheat. J. Appl. Microbiol. 46:473-480

Khan, A., Zhao, X.Q., Javed, M.T., Khan, K.S., Bano, A., Shen, R.F. and S. Masood.2016. Bacillus pumilus enhances tolerance in rice (Oryza sativa L.) to combined stresses of $\mathrm{NaCl}$ and high boron due to limited uptake of $\mathrm{Na+}$. Environ. Exp. Botany. 124: 120-129.

Kumar, S., Dwivedi, S.K., Singh, S.S., Bhatt, B.P., Mehta, P., Elanchezhian, R., Singh, V.P. and O.N. Singh. 2015. Morpho-physiological traits associated with reproductive stage drought tolerance of rice (Oryza sativa L.) genotypes under rain-fed condition of eastern Indo-Gangetic Plain. Ind. J. Plant Physiol. 19(2):87-93.

Kumar, A.S., Sridar, R. and S.Uthandi.2017.Mitigation of drought in rice by a phyllosphere bacterium Bacillus altitudinis FD48. Afr. J. Microbiol. Res. 11(45):1614-1625.

Lata, C., Muthamilarasan, M. and M. Prasad. 2015. Drought stress responses and signal transduction in plants, in: Pandey, G.K. (ed.), Elucidation of abiotic stress signaling in plants. Springer, NewYork, pp. 195-225.

Martins, S.J., Medeiros, F.H., Lakshmanan, V. and, H.P. Bais. 2018. Impact of seed exudates on growth and biofilm formation of Bacillus amyloliquefaciens ALB629 in common bean. Front. microbiol. 8: p.2631. 
Muscolo, A., Sidari, M., Anastasi, U., Santonoceto, C. and A. Maggio. 2014. Effect of PEG-induced drought stress on seed germination of four lentil genotypes. J. Plant Interact. 9(1): 354-363.

Nauriere, C., Doyen, C., Thevenot, C. and J. Dauffant. 1992. $\beta$-amylase in cereals: study of the maize $\beta$-amylase system. Plant Physiol. 100:887- 893.

Nelson, E.B. 2004. Microbial dynamics and interactions in the spermosphere. Annu. Rev. Phytopathol. 42:217-309.

Ng, L.C., Sariah, M., Sariam, O., Radziah, O. and M.A. Zainal Abidin. 2012. Rice seed bacterization for promoting germination and seedling growth under aerobic cultivation system. Aus. J. Crop Sci. 6(1): 170.

Preeti, V., Reddy, M.S., Kavitha, S., Velusamy, P., Paulraj, R.S.D., Purushothaman, S.M., Priyadarisini, V.B., Bharathkumar, S., Kloepper, J.W. and S.S. Gnanamanickam. 2002. Role of biological preparations in enhancement of rice seedling growth and grain yield. Curr. Sci. 83:1140-1143

Punitha, S., Kalarani. M.K. and U. Sivakumar.2019. Apoplast associated Bacillus methylotrophicus RABA6 induced growth and yield attributes leading to drought tolerance in Rice. Madras Agric.J. doi:10.29321/MAJ 2019.000273.

Rana, A., Kabi, S.R., Verma, S., Adak, A., Pal, M., Shivay, Y.S., Prasanna, R. and L. Nain. 2015. Prospecting plant growth promoting bacteria and cyanobacteria as options for enrichment of macroand micronutrients in grains in rice-wheat cropping sequence. Cogent Food \& Agriculture. 1(1): 1-16

Ryu, C.M., Farag, M.A., Hu, C.H., Reddy, M.S., Kloepper, J.W. and P.W. Pare. 2004. Bacterial volatiles induce systemic resistance in Arabiropsis. Plant Physiol. 134:1017-1026.

Sarcheshmehpour, M., Savaghebi, G.R., Siadat, H. and H.A. Alikhani. 2013. Effect of plant growth promoting rhizobacteria on improvement of nutrition and growth of pistachio seedling under drought stress. Ira. J. Field crops and sci. 27(1):107-119.
Schiltz, S., Gaillard, I., Pawlicki-Jullian, N., Thiombiano, B., Mesnard, F. and E. Gontier. 2015. A review: what is the spermosphere and how can it be studied?. J. Appl. Microbiol. 119(6): 1467-1481.

Shu, X.L., Frank, T., Shu, Q.Y. and K.H. Engel. 2008. Metabolite profiling of germinating rice seeds. .J. Agric. Food Chem. 56: 11612-11620.

Sun, C., Johnson, J.M., Cai, D., Sherameti, I., Oelmüller, R., B. Lou. 2010. Piriformospora indica confers drought tolerance in Chinese cabbage leaves by stimulating antioxidant enzymes, the expression of drought-related genes and the plastid-localized CAS protein. J. Plant Physiol. 167: 1009-1017.

Tiwari, S., Lata, C., Chauhan, P.S. and C.S. Nautiyal. 2016. Pseudomonas putida attunes morphophysiological, biochemical and molecular responses in Cicer arietinum L. during drought stress and recovery. Plant Physiol. Biochem. 99:108-117.

Vacheron, J., Desbrosses, G., Bouffaud, M.L., Touraine, B., Moënne-Loccoz, Y., Muller, D., Legendre, L., Wisniewski-Dyé, F. and C. Prigent-Combaret. 2013. Plant growth-promoting rhizobacteria and root system functioning. Front. Plant Sci. 4 :356.

Weitbrecht, K., Müller, K. and G.Leubnermetzger. 2011. First off the mark: early seed germination. J. Exp. Bot. 62: 3289-3309.

Wolfender, J.L., Marti, G., Thomas, A. and S. Bertrand. 2015. Current approaches and challenges for the metabolite profiling of complex natural extracts. $J$ Chromatogr A. 1382: 136-164.

XLSTAT (2010) XLSTAT. Addinsoft SARL, Paris. http:// www.xlstat.com.

Yemn, E.W. and A.J. Willis. 1954. The estimation of carbohydrates in plant extracts by anthrone. Biochem J. 57: 508-514.

Zeid, I.M. and Z.A. Shedeed. 2006. Response of alfalfa to putrescine treatment under drought stress. Biol Plant. 50: 635640. 